\title{
Nano Research Trends of Critical Scientific Fields Across Leading Worldwide Geo-Economic Players and Their Spatial Interactions
}

\author{
Mario Coccia ${ }^{1,2}$, Ugo Finardi ${ }^{1,3, *}$ and Diego Margon ${ }^{1}$ \\ ${ }^{1}$ National Research Council of Italy, CERIS-CNR, Moncalieri- Torino \\ ${ }^{2}$ Georgia Institute of Technology, School of Public Policy, Atlanta \\ ${ }^{3}$ Università di Torino, Dipartimento di Chimica I.F.M. \\ 1,3 Italy \\ ${ }^{2}$ USA
}

\section{Introduction}

Nanotechnologies are one of the NBIC "converging technologies" (Nanotechnologies, Biotechnologies, Informatics and Cognitive Sciences) that are foreseen to change the world in the next future (Roco 2008; Linstone 2011). Nanoscience and, in particular, nanotechnologies are a new "technological system" (Freeman and Soete, 1987, p. 67). Nanoscience studies are flourishing in several countries and scientists tend, more and more, to publish on some critical research topics such as recently invented nanomaterials, new techniques that are suitable to study and characterize them, preparation techniques and substances used to produce nanomaterials and nanostructured objects, properties and technological uses of nanostructured materials and so on (cf. Islam and Miyazaki, 2010; Islam and Miyazaki, 2009; Bainbridge and Roco, 2006; Coccia et al. 2011). The importance of nanotechnologies and nanoscience has begun to go beyond the bare entourage of laboratories and research centres and is nowadays well present everywhere industrial innovation takes place (Goddard III et al., 2007). In fact, nanotechnological innovations are critical in several industries such as microelectronics, chemistry, public health, environment, etc. (see Bainbridge and Roco, 2006; Pilkington et al., 2009; Tegart, 2009; Glenn, 2006; van Merkerk and van Lente, 2005).

The spreading of nanotechnology in basic sciences and in applied research has also caused the insurgence of great interest towards their study by economics of science and innovation (cf. Bozeman et al., 2007, Rogers, 2010, Coccia, 2011, Coccia 2012). In fact, there is a vital interest to analyze the technological trajectories of nanotechnology and the specificity of countries in nanoscience production and its application in order to forecast research trends and future effects onto industrial dynamics across countries (cf. Salerno et al., 2008; Bainbridge and Roco, 2006; de Miranda Santo et al., 2006; Avenel et al., 2007).

${ }^{*}$ Correspondig Author 
The purpose of this paper is to analyze the current technological trajectories and interaction in nanoscience and nanotechnology studies across worldwide economic players. In particular, the main research questions addressed are:

- Which are the current driving research fields where nanotechnologies have been developing?

- Which is the behaviour of leading geo-economic areas in the production of nanoscience and nanotechnology knowledge?

- Which is the intensity of scientific collaborations across leading geo-economic players?

The study here analyzes the codified scientific production in this vital "technological system" to show how different geo-economic regions (such as the North America and Europe) have acted and reacted towards nanotechnology studies, and how they have been behaving over time in the scientific knowledge production and international collaboration in Nanoscience and Nanotechnologies (NSTs). This research can provide main findings in order to understand the current worldwide research trends in NSTs. This is important to support modern innovation policies aimed at improving the development of such converging technologies able to support future patterns of economic growth.

This paper presents in section 2 a theoretical framework about nanotechnologies and nanosciences; section 3 describes the methodology of research, whereas section 4 analyzes the results and section 5 discusses lessons learned.

\section{Theoretical background}

"Nanoscience is the result of interdisciplinary cooperation between physics, chemistry, biotechnology, material sciences and engineering towards studying assemblies of atoms and molecules" (Renn and Roco, 2006, p. 154)1.

The "birth certificate" of NSTs, at least from the conceptual point of view, is considered the renowned speech given at the American Physical Society meeting held at California Institute of Technology by Richard P. Feynman (1960), where the 1964 Nobel Prize Laureate uttered the famous sentence "There is plenty of room at the bottom" talking about the opportunities for science and technology given by the vast expansion of scientific and technological research towards the nanometric dimensional range and describing molecular machines built with atomic precision. The first use of the word "nano-technology" instead has to be assigned to Taniguchi (1974) of Tokyo Science University, who used it in an article on ionsputtering machining.

Since then, the spreading and growth of NSTs has been marked by inventions and findings in terms of new nanostructured materials, investigation and characterization techniques, and new nano-objects. By the operational point of view, one of the most common opinion is that NSTs did originate in 1981 with the creation of Scanning Tunnelling Microscope (STM) in the IBM laboratories in Zurich, by 1986 Nobel Prizes Laureates for Physics Gerd K. Binnig and Heinrich Rohrer. From the point of view of nanostructured materials 1985 marks the discovery of Buckyball (Buckminsterfullerene) by Kroto and Smalley (the discovery will

${ }^{1}$ Cf. also Roco, 2007, pp. 3.1-3.26. 
gain them the Nobel Prize in Chemistry in 1996, see Kroto et al., 1985); 1990 the discovery of Silica mesoporous materials by Yanagisawa and co-workers at Waseda University in Tokio (Yanagisawa et al., 1990); 1991 the discovery of Carbon nanotubes by Iijima (1991) at NEC Corp. By the point of view of new nanostructured objects, it is remarkable the work performed by Eigler and Schweizer (1990) who did spell the IBM logo in individual atoms on a nickel surface. Several scientific journals having the stem "nano" on their title are published nowadays.

NSTs represent mostly an approach to science, technology and innovation rather than a specific sector by itself. For instance, the website of the American National Nanotechnology Initiative ${ }^{2}$ states $^{3}$ :

"Nanoscience involves research to discover new behaviours and properties of materials with dimensions at the nanoscale which ranges roughly from 1 to 100 nanometres (nm). Nanotechnology is the way discoveries made at the nanoscale is put to work. Nanotechnology is more than throwing together a batch of nanoscale materials - it requires the ability to manipulate and control those materials in a useful way.

Nanotechnology is the understanding and control of matter at dimensions between approximately 1 and 100 nanometers, where unique phenomena enable novel applications. Encompassing nanoscale science, engineering, and technology, nanotechnology involves imaging, measuring, modelling, and manipulating matter at this length scale [...] Unusual physical, chemical, and biological properties can emerge in materials at the nanoscale. These properties may differ in important ways from the properties of bulk materials and single atoms or molecules."

By one side the definition discriminates between science and technology, which is sometimes hard to tell. But on the other side, it describes precisely and briefly the fundamental characters of NSTs: they act in a well defined dimensional field and this is substantial and cannot be disregarded; purpose is discovering new behaviours and properties distinctive of materials when nanostructured. From this point onwards, technologies have the purpose of transforming the new knowledge in innovation.

As we can define NSTs as an approach towards matter, when we discuss the transfer of nanoscience into technological innovation, as far as the "transversal" character of NSTs has been defined, it is clear that we cannot talk about "application sectors" of NSTs. This, not because nanotechnologies cannot be applied to industrial innovation and to the production of goods, but, on the contrary, because the list of sectors is virtually endless.

The technological application of NSTs has been first of all in niche industries, mostly knowledge-intensive and with high-added-value products, such as the production of catalysts for industrial production (cf. Zecchina et al., 2007; Evangelisti et al., 2007) or biomaterials produced for bone substitution inside the human body (cf. Bertinetti et al., 2006; Celotti et al., 2006) and so on. In these cases, the distance existing between basic/purpose-

\footnotetext{
${ }^{2}$ See: http://www.nano.gov/Nanotechnology_BigThingsfromaTinyWorldspread.pdf (accessed July 2010); http://www.nano.gov/html/facts/whatIsNano.html; accessed July 2010.

${ }^{3} \mathrm{Cf}$. also Siegel et al., 1999.
} 
free research and technological innovation is almost not existing, or very narrow, and the high added value of goods justifies the economic engagement of the scientific research.

Other edge industries where the use of nanotechnologies is established are those of biotechnologies and electronics: Bioelectronics. In this last case the downscaling of circuitry - until and below limit of $45 \mathrm{~nm}$ (nanometers) - has mostly benefited of the extreme frontier of manipulation technologies in order to reach a higher miniaturization.

NSTs are not only transversal to possible industrial applications, but also to scientific sectors: e.g. material sciences, chemical and physical sciences, and material engineering. Different traditional scientific fields have in general a different approach towards NSTs, as well described by Balzani (2005) who gives his own definition of sciences and technologies, and underlines the different approaches adopted towards NSTs by different categories of scientists. The typical approach of physicists and engineers is the so-called top-down approach, where the matter is manipulated instrumentally - e.g. with the techniques of photolithography - in order to obtain the desired results: in this way the dimensional barrier of 100 nanometers has been a hard one to overcome.

The typical approach of chemists is exactly reverse to the previous one: a bottom-up approach where objects lying in the molecular dimensional domain - thus around and slightly below the nanometer - can be used as "bricks" to build nanostructured objects with bigger dimensions, such as the molecular computers with high scientific and technological content in the quest for an innovating application.

Nanotechnologies are nowadays fully inserted in the paths of "creative destructions" generated by technical knowledge in industries (Bozeman et al., 2007). NSTs are at the convergence of several scientific and technological fields and affect the economic system by the emergence of new industries (Bainbridge and Roco, 2006). Moreover, university spinouts in NSTs are gaining importance and are playing a critical role for regional development (Libaers et al., 2006). NSTs are also in a cutting-edge position in order to enhance new systems for environmental control and remediation, though some envisage dangers from their use (Rickerby and Morrison, 2007).

Scientometrics studies are effective approaches to analyze the emergence and development of research fields in nanotechnology (Braun et al., 1997; Rogers, 2010). Salerno et al. (2008) argue that: "Bibliometric analysis of publications [...] can help have a synthetic picture of the best players at a worldwide level, their lines of inquiries and their relationships, that is, they could help to cope with the extremely fragmented knowledge, actors and applications involved in the evolution of the field" (p. 1220). Leydesdorff and Zhou (2007), basing their work on Journal Citation Report data shows that "nano" journals have more complex content than other journals - from the point of view of citations - and their position is at the interface between physics and chemistry. In fact, Leydesdorff (2008) also shows the growing interdisciplinary effects of NSTs. Kostoff et al. (2006; 2007; 2007a) describe an overview on the NSTs literature and show the continuous evolution and growth in NSTs, driven by Asian countries. Schultz and Joutz (2010) perform a patent analysis on USPTO nanotechnology patents. Several patents clusters are identified using citations; this leads to affirm that a handful of very general nanotechnologies are developing, with the potential for a wide economic impact. 
Nanostructured materials and nanotech production processes are being developed for use in a wide range of sectors (p. 167). Also Shea et al. (2011) analyze the same data source with a descriptive statistic analysis, and show similar results. Finardi (2011) uses citations of journal articles in patents to calculate the time elapsed between scientific activities and patenting of technology in NST. Findings show a time distance of 3-4 years between the two activities, while other similar fields show very different behaviour.

It is then obvious from this theoretical background that a deep scientific analysis of research trends and interaction in the scientific production of NSTs across leading worldwide players is an important topic to be developed in order to understand the current technological trajectories that may support future spatial patterns of economic growth.

\section{Strategy of research}

This paper uses Scopus database: "Scopus is the largest abstract and citation database of peer-reviewed literature and quality web sources with smart tools to track, analyze and visualize research. It's designed to find the information scientists need [...] Scopus provides superior support of the literature research process" (Scopus, 2010) 4 .

Scopus has been preferred to other analogous web-databases because:

- It encompasses a wider set of data: "With over 18,000 titles from more than 5,000 publishers, Scopus offers researchers a quick, easy and comprehensive resource to support their research needs in the scientific, technical, medical and social science fields and, more recently, also in the arts and humanities" 5 .

- It has the broadest available coverage, with more than half of the content originating from Europe, Latin America and the Asia Pacific region'6.

- It has a wide set of data retrieval instruments, useful in performing Data Mining.

- It exploits a system of classification of titles under categories: "Titles in Scopus are classified under four broad subject clusters (Life Sciences, Physical Sciences, Health Sciences and Social Sciences \& Humanities) which are further divided into 27 major subject areas and 300 minor subject areas. Titles may belong to more than one subject area"7.

Data mining from Scopus (2010) was performed using the following methodology:

a. the search of "nano" 8 on "Article Title, Abstract, Keyword" is made;

b. on the selected records a further refinement is performed using the "Refine results" frame, selecting only those records containing one or more of the following keywords: "Nanostructured materials", "Nanotechnology" or "Nanostructures".

\footnotetext{
${ }^{4}$ http://info.scopus.com/about/ (accessed 11 June 2010); See also http://info.scopus.com/whyscopus/academia/ (accessed June 18 $8^{\text {th }}, 2010$ ).

${ }^{5} \mathrm{http}: / /$ info.scopus.com/scopus-in-detail/content-coverage-guide/ (accessed June 18 $8^{\text {th }}, 2010$ ).

${ }^{6} \mathrm{http}: / /$ info.scopus.com/scopus-in-detail/facts/ (accessed July 1 st, 2010).

${ }^{7} \mathrm{http}: / /$ info.scopus.com/scopus-in-detail/content-coverage-guide/journalclassification/ (accessed June 18th, 2010).

$8 "$ "*" is the usual dummy meaning "any series of character after the ones written"
} 
In particular, Data Mining is performed on:

- $\quad$ Time Horizon from 1996 to 2008 in order to analyze the temporal research trends and scientific interactions. Within the range 1996-2008 we have the opportunity to retrieve all information analyzed, whereas this is not possible for year before 1996 (when Scopus starts gathering full data) and after the 2008 (as Data Mining was performed in January 2010).

- Key geo-economic areas: selected areas have been USA and Canada, South Korea, Japan, China and Europe 9 . These geo-economic and politic areas are the main worldwide players in the production of nanotechnology and nanoscience studies.

After that quantitative data have been retrieved, we have main information about several characteristics of scientific products in NSTs. In particular, we show the affiliations of authors (i.e. main research institutions and/or labs where the research is carried out by scholars) and the subject areas ${ }^{10}$ of nanoscience and nanotechnology studies published on leading scientific journals. Our samples are based on the 149,324 scientific products (e.g. Articles, Proceedings, etc.) on nanotechnology studies with their affiliations (about $96 \%$ of main research centres operating in NSTs) retrieved as above described per countries and years. As papers concerning the nanotechnology studies are published on journals that are classified per 28 subject areas ${ }^{10}$, the 149,324 scientific products have almost 400,000 occurrences of subject areas. In general, the number of occurrences of subject areas by journals is greater than the total number of scientific products (i.e. papers) ${ }^{11}$. The occurrences of articles represent a view of subject areas in nanotechnology studies and how much attention they have received in the scientific literature.

The vast sample of papers classified by Scopus in main subject areas has been aggregated in five "Macro Subject Areas": Material Science, Chemistry and Medicine, Physics and Earth Sciences, Engineering; all marginal areas of nanotechnology studies (less than 5\% of the sample) have been included under the category "Others" (Information and Mathematics Sciences, Social and Economic Sciences, Energy, Environmental Science). Table 1A in Appendix shows the number of scientific products (mainly papers) per each Macro Subject Area. This aggregation has been important to show the temporal and spatial pattern of nanotechnology research trends across countries. The more detailed analysis per keywords has not been considered first of all because of the high number of generic keywords like "Synthesis", "Chemistry", "Priority journal", "Crystallization", "Methodology" etc. Moreover single keywords do not refer necessarily to a single research field, making such an

\footnotetext{
${ }^{9}$ In "Europe" the selected countries are: Albania, Austria, Belarus, Belgium, Bosnia, Bulgaria, Croatia, Czech Republic, Estonia, Finland, France, Germany, Greece, Holland, Hungary, Ireland, Italy, Latvia, Lithuania, Macedonia, Moldova, The Netherlands, Norway, Poland, Portugal, Romania, Russia, Serbia, Slovakia, Slovenia, Spain, Sweden, Switzerland, Ukraine, and United Kingdom.

${ }^{10}$ Scopus classifies journals in major subject areas, such as "Energy", "Chemistry", "Engineering", etc. Journals can be allocated to multiple subject areas as appropriate to their scope. We use all subject areas containing papers on nanotechnology studies. Interestingly, the average number of subject areas that journals in the "Energy" papers belong to (2.09) is higher than the average value of all science (1.37), indicating that they exhibit a strong degree of interdisciplinarity.

${ }^{11}$ For instance a paper about the nanotechnology published on the journal Scientometrics, is one paper with 3 subject areas, since Scientometrics is classified with three subject areas (computer science applications, social sciences and library and information sciences).
} 
analysis less meaningful. Also the categorization of research domains in "nanomaterials" and "nanoelectronics" has not been considered because of their inner overlaps: nanomaterials are heavily applied in nanoelectronics; therefore considering this categorization is not fruitful for investigating the real nanotechnology research trajectories and could bring to ambiguous results and misleading research trends. Vice versa, the aggregate sets applied in this research provide more accurate and robust results about the temporal and spatial research trends.

Another main scientometric analysis performed is based on the scientific interaction in nanotechnology production across geo-economic areas. We have considered in each geographical area, for its scientific output, the foreign affiliations in nanotechnology studies in order to see the mutual scientific interaction for nano scientific research production.

The main limit imposed by Scopus search engine is the maximum of 160 items (the most represented ones) for each data mining. Other limits could be the fact that NSTs are not present as an autonomous subject area in Scopus (limit overcome with our Data Mining) and not all papers/proceedings in nanotechnology studies are captured and included in Scopus dataset. Nevertheless this is also a weakness point for other web-based data collections. The information analysis of our samples is carried out by statistical and graphs analysis considering some critical research fields and geo-economic areas in order to show driving research trends and interaction in nanotechnology studies.

\section{Empirical analysis}

This paper analyzes five main geo-economic areas in the production of nanotechnology, based on research centres and their scientific output present into Scopus (2010). For what about the structure of domestic research centres, their aggregate number has been calculated assigning the respective geo-economic area (of the primary physical base) to all occurrences of affiliations present in our databases producing at least a scientific product in nanotechnologies. The highest number of research labs in nanotechnology over 19962008 period is in Europe and North America (i.e. USA and Canada), see Figure 1. Europe and North America have in 2008 about 150 research centres operating in nanotechnology fields. Japan has a lower number of research centres if compared with previously described leading geo-economic areas, with roughly 100 units, with a stable cumulative temporal number in the range 107-117. China and South Korea are the two geo-economic areas where the number of nanotechnology research centres has been increasing, reducing in 2008 the high gap presents in 1996 in comparison with the level of Europe and North America ${ }^{12}$ : in particular, China has more than 130 nanotechnology research centres operating in 2008 (Table 2A in Appendix shows the cumulative number of these research centres over 1996-2008, across geo-economic areas, and their scientific outputs in the last 15 years).

Figures 2-6 show the main research fields of nanoscience studies from 1996 to 2008 across worldwide geo-economic areas. As the absolute numbers of scientific products across geo-

\footnotetext{
${ }^{12}$ Cf. de Miranda Santo et al. (2006) pp. 1022ff.
} 
economic areas are not suitable values for reliable spatial and temporal comparisons (as research trends are similar), we apply percent values to analyze the mutual temporal dynamics within research fields in NSTs. These trends show some common patterns: although the nanotechnology studies in material science have an higher scientific production in comparison with other macro subject areas (see table 1A), the internal dynamics among macro subject areas shows mainly a relative reduction over time and space of studies in nanomaterial sciences (decreasing returns to production), whereas the studies of nanotechnology applied in Chemistry and Medicine have been increasing. In addition, the highest relative increase of nanoscience studies in Chemistry and Medicine, measured by coefficients of regression lines, is in China $(\beta=2.2)$ and South Korea $(\beta=1.95)$, whereas the lowest magnitude is in Japan $(\beta=1.4)$. These results indicate that some nanotechnology research domains which have generated main inventions of several nanomaterials are mature research fields, whereas nowadays studies of nanotechnology in Chemistry and Medicine have been growing because modern research centres focus their scientific research on critical innovations in more applied sectors of NSTs. This means that some nanotechnology trajectories have been passing from invention to innovation phase.

Nano-sciences studies in "Physics and Earth Sciences" have roughly a relative steady declining trend across geo-economic areas. Studies of nanotechnology in Engineering sciences have also a steady trend across the areas, except for Japan that shows an unstable increasing temporal trend. The results are confirmed by Figure 7, for all geo-economic areas. As the driving nanotechnology studies in "Chemistry and Medicine" have been increasing in the last 15 years with a relative high rate of growth, due to the high number of applications (innovations) in several research fields, the inner dynamics have been divided in two periods (1996-2002 and 2002-2008) in order to capture the temporal paths across countries. Figure 8 shows a relative critical role, over 1996-2002 period, by Europe and USACanada, followed by Japan (Third position). If this analysis is repeated over 2002-2008 period (see Figure 9), nanotechnology studies in Chemistry and Medicine carried out in China have been increasing, predominating over the trend of Japan ${ }^{13}$ (Figures 1A and 2A in Appendix show the absolute and percent values of scientific products concerning nanotechnology studies applied in Chemistry and Medicine across geo-economic areas).

Figure 10 shows the driving Subject Areas of nanotechnology studies within the macro subject area "Chemistry and Medicine": e.g. Chemical engineering, Biochemistry, Pharmaceutics, etc.; these subject areas confirm the innovation phase of the dynamics of some nanotechnology trajectories.

As far as the nanotechnology studies in "Material sciences" are concerned, the leading countries are mainly Europe and China over 1996-2008 period (Figure 11), although the relative role of China has been increasing over 2002-2008 (Figure 12). Other macro areas, i.e. "Physics and Earth Sciences" and "Engineering", show the leadership of Europe and USACanada. For the sake of briefness some figures are not reported.

\footnotetext{
${ }^{13}$ de Miranda Santo et al. (2006) confirm the great contribution of China to scientific research in nanoscience and nanotechnology in the group of competitor countries (p. 1024).
} 


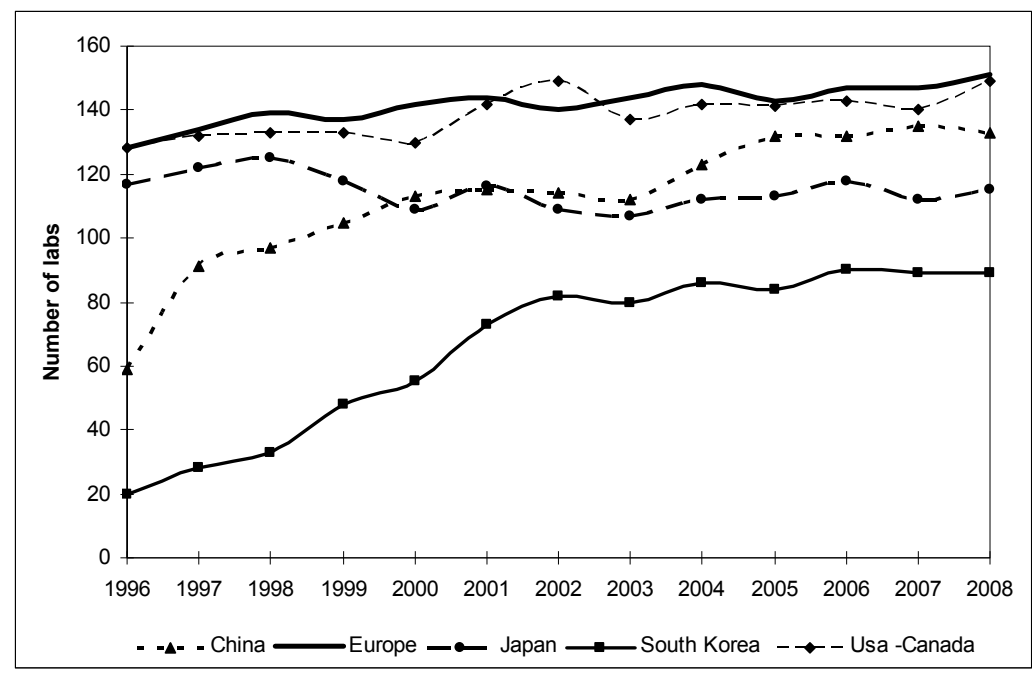

Fig. 1. Research Centres operating in nanotechnology across countries, 1996-2008 period

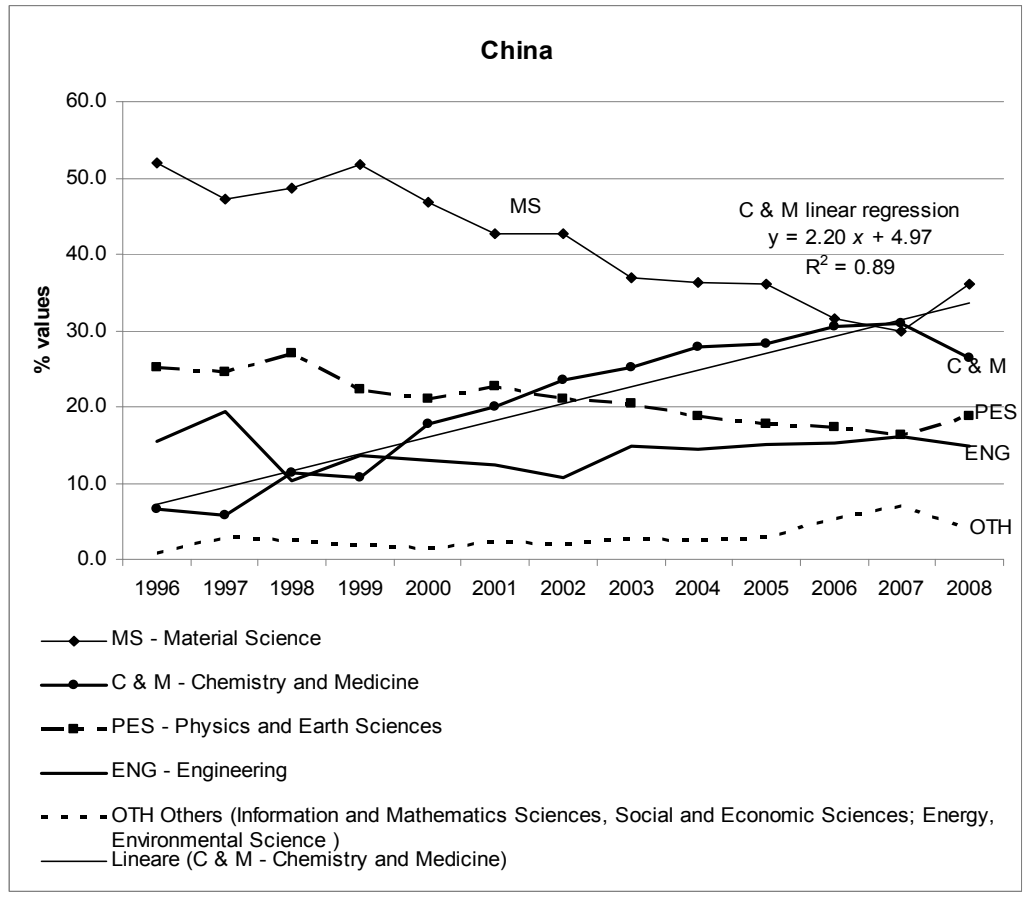

Fig. 2. Research trend measured by number of papers in nanotechnology studies (\% values) classified per macro subject areas - China 


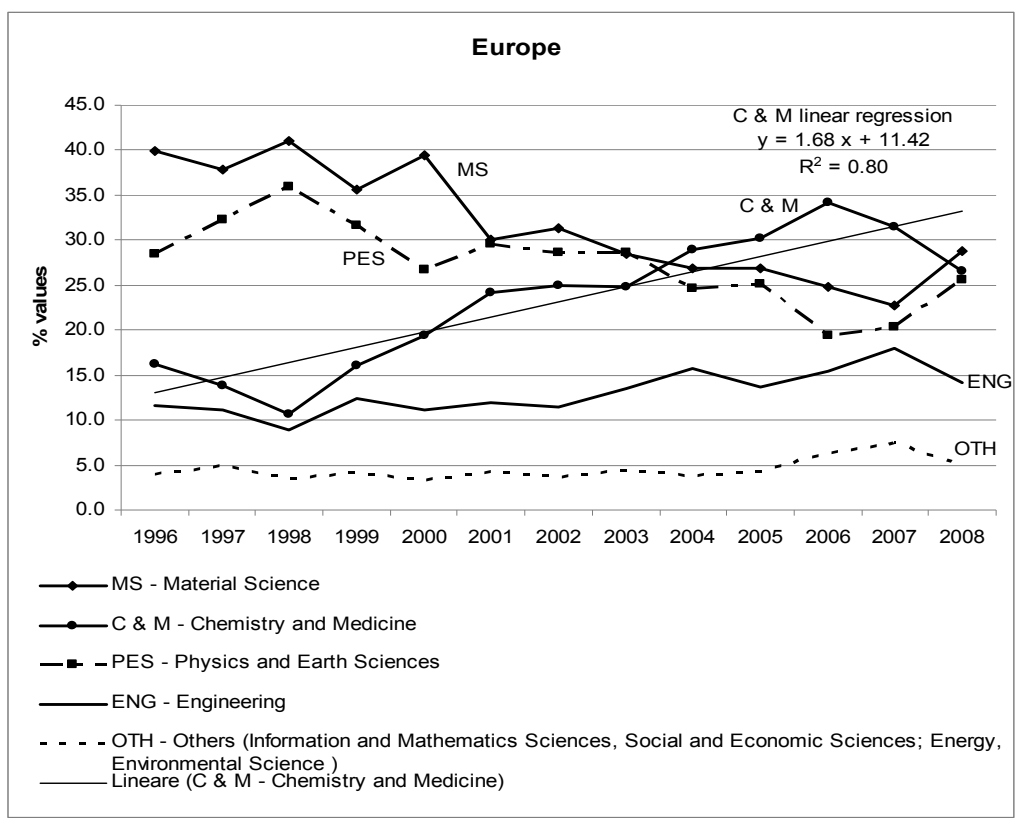

Fig. 3. Research trend measured by number of papers in nanotechnology studies (\% values) classified per macro subject areas - Europe

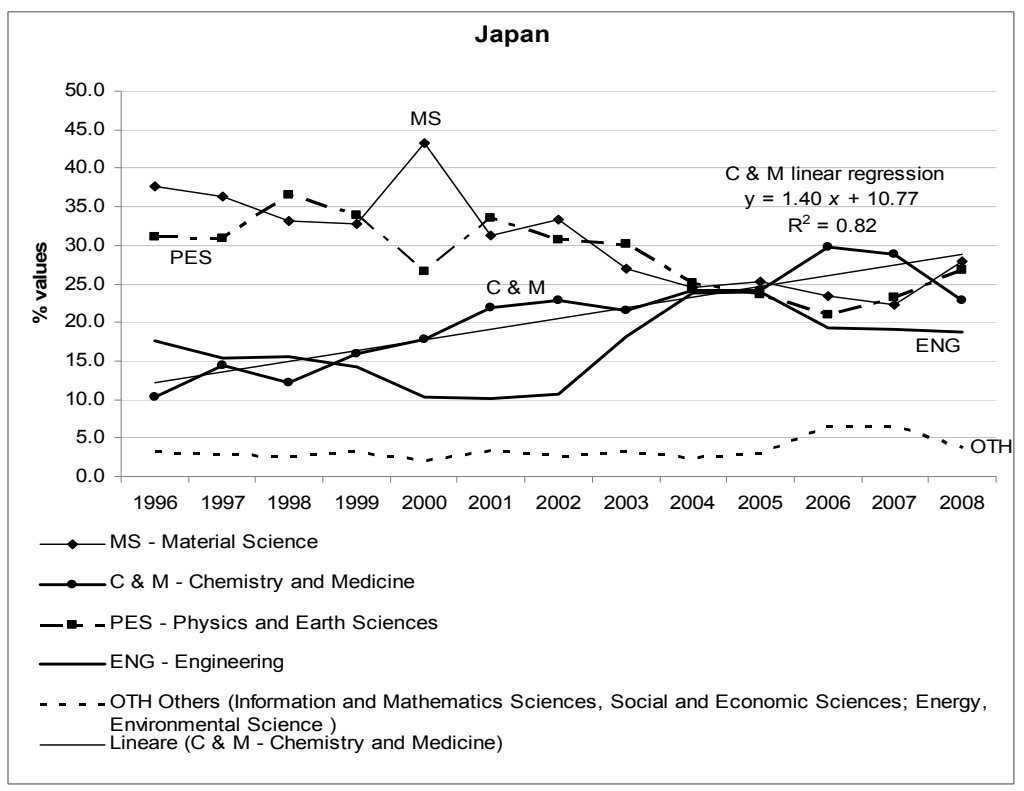

Fig. 4. Research trend measured by number of papers in nanotechnology studies (\% values) classified per macro subject areas - Japan 


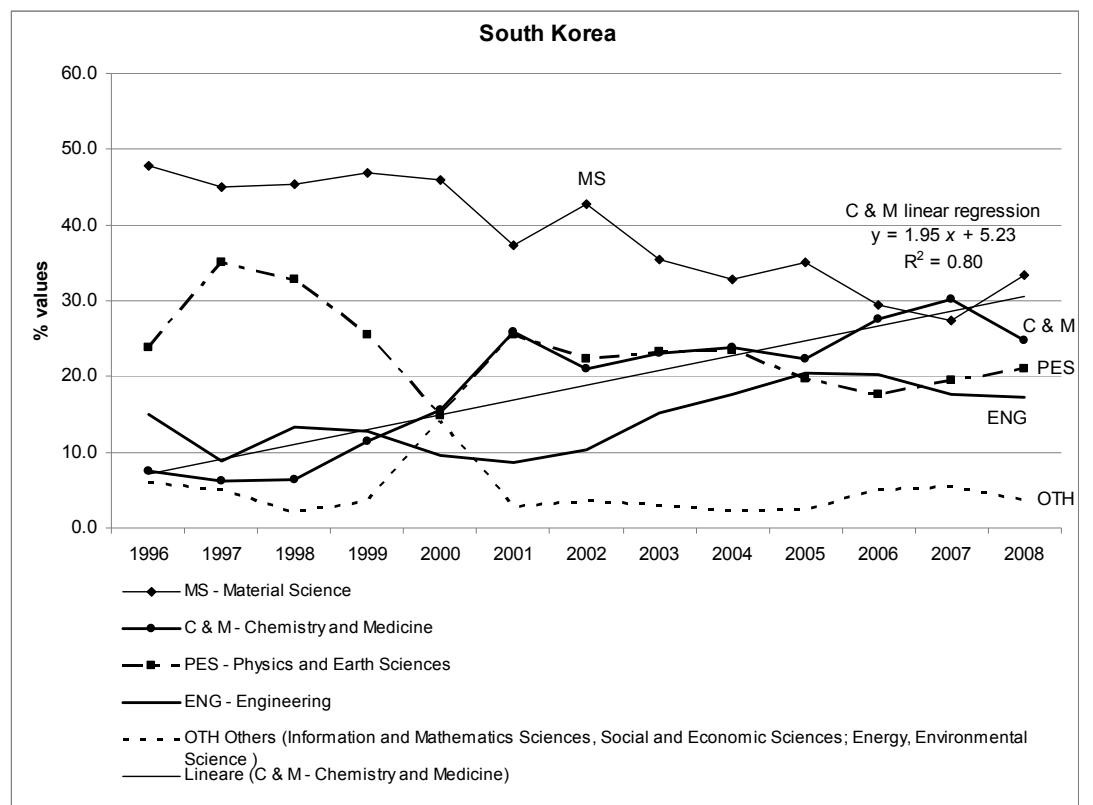

Fig. 5. Research trend measured by number of papers in nanotechnology studies (\% values) classified per macro subject areas - South Korea

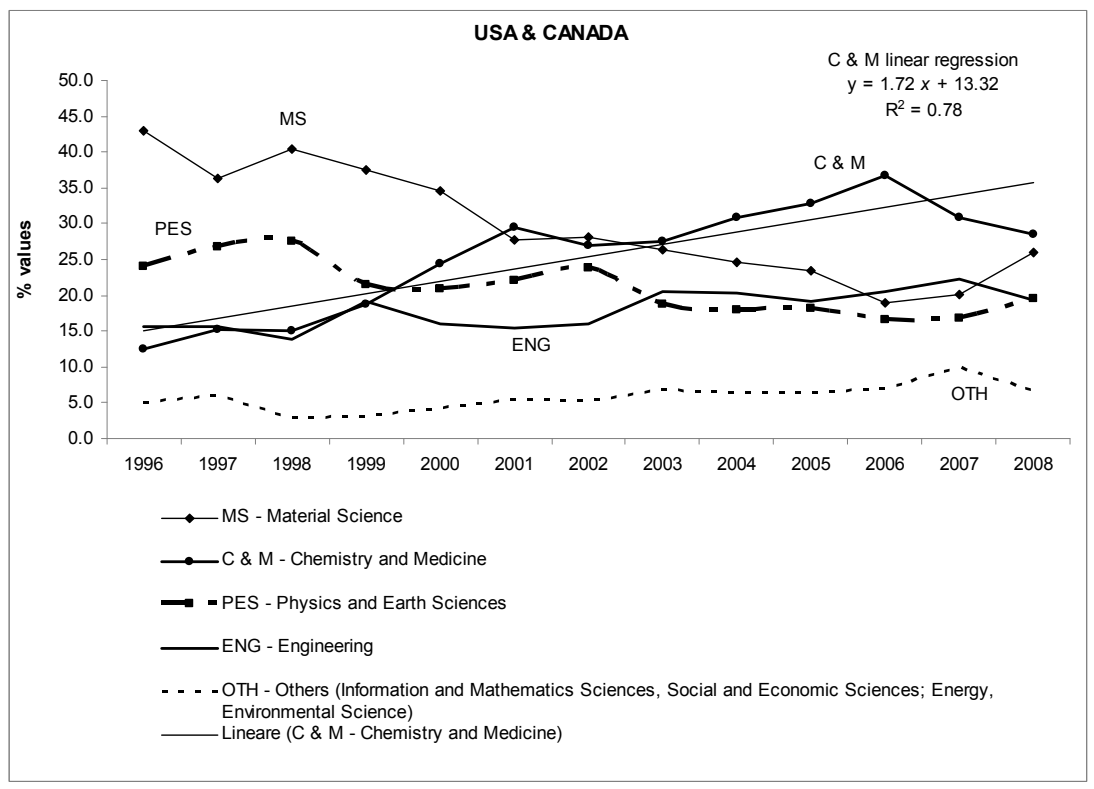

Fig. 6. Research trend measured by number of papers in nanotechnology studies (\% values) classified per macro subject areas - USA \& Canada 


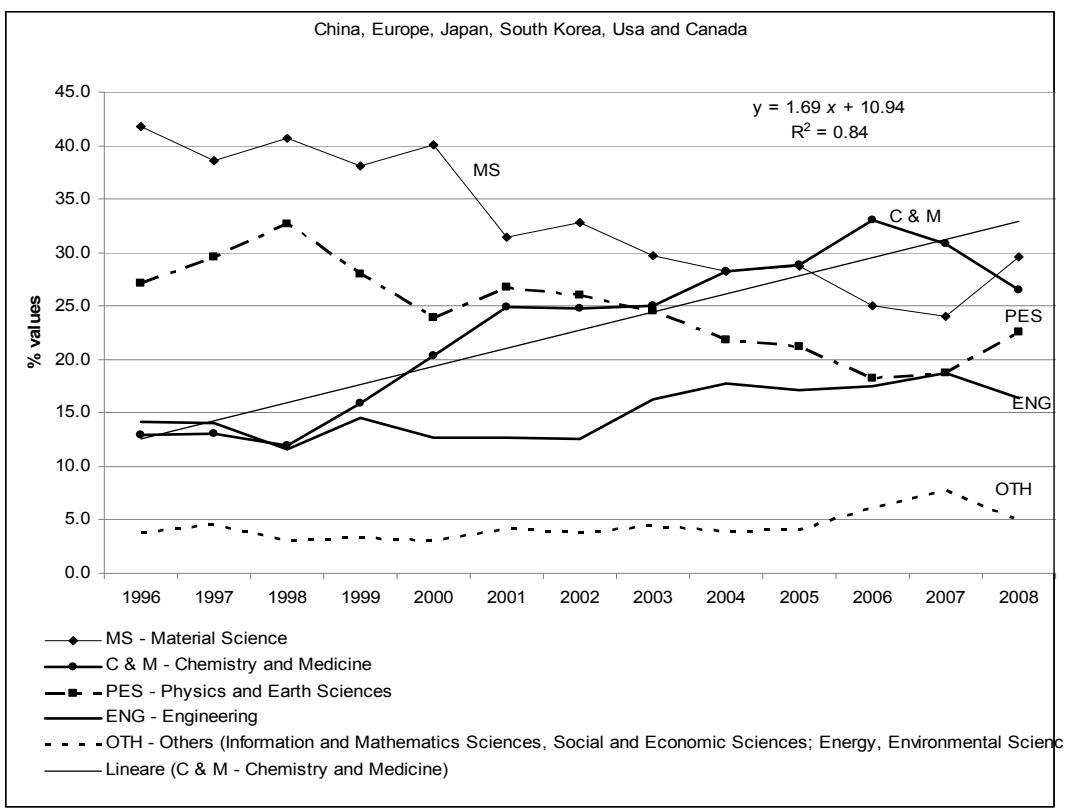

Fig. 7. Research trend measured by number of papers in nanotechnology studies (\% values) classified per macro subject areas - All geo-economic areas

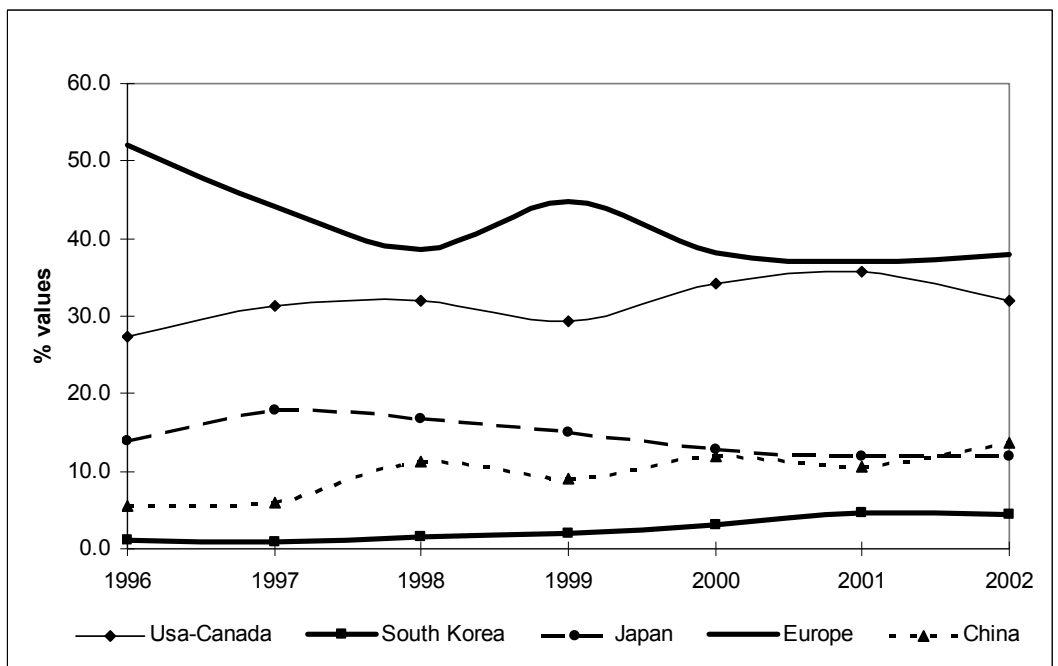

Fig. 8. Research trend per geo-economic areas measured by number of papers in nanotechnology studies classified in Chemistry and Medicine over 1996-2002 (\% values) 


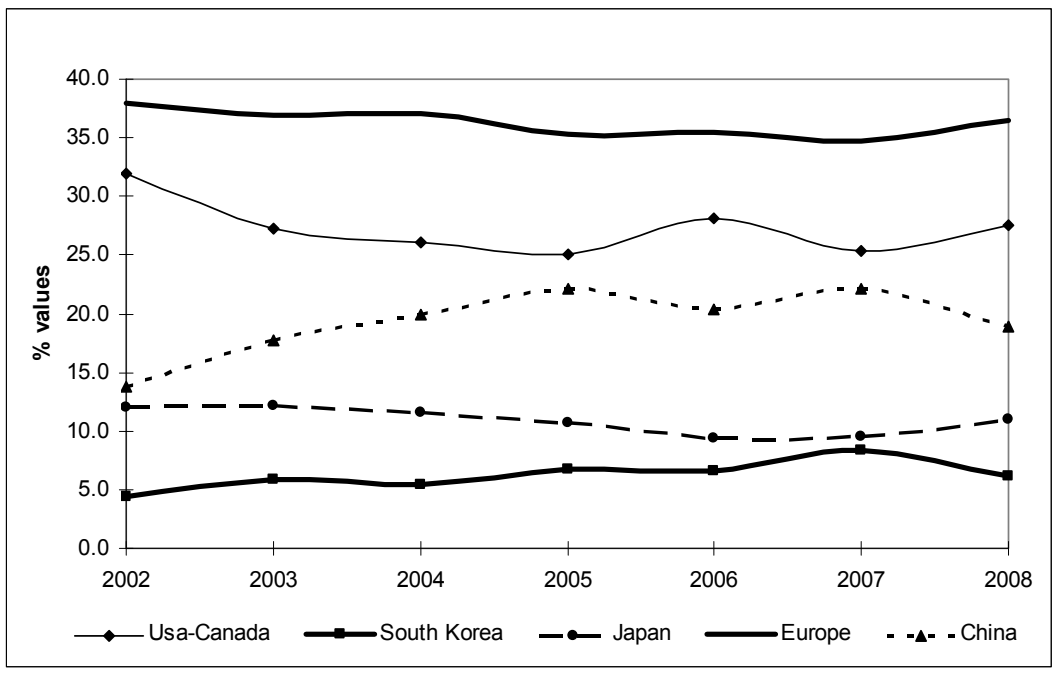

Fig. 9. Research trend per geo-economic areas measured by number of papers in nanotechnology studies classified in Chemistry and Medicine over 2002-2008 (\% values)

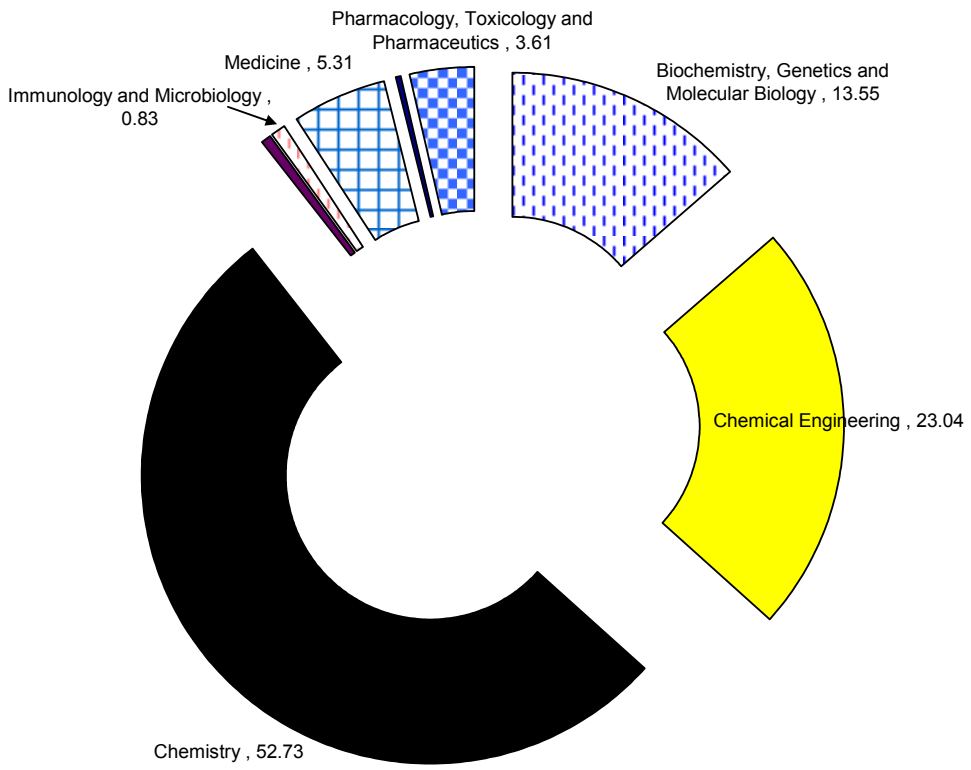

Fig. 10. Percent value of main research fields of nanotechnology studies applied in Chemistry and Medicine

Another main result is shown in figure 13 about the mutual scientific interaction across geoeconomic areas in nanotechnology studies. Although each geo-economic area has a vast 
production of scientific output within domestic nanotechnology research centres (about $90 \%$ ), the residual is carried out in collaboration with foreign scholars and research centres. The results are: labs of Europe and USA-Canada have a high capacity of attraction of foreign scholars in the scientific research on nanotechnology and nanoscience, measured by joint affiliations in papers (see the simple bars above the $x$-axis in figure 13), whereas South Korea and China are the two geographic areas having the highest number of scientific collaborations with other scientific players in nanotechnology studies.

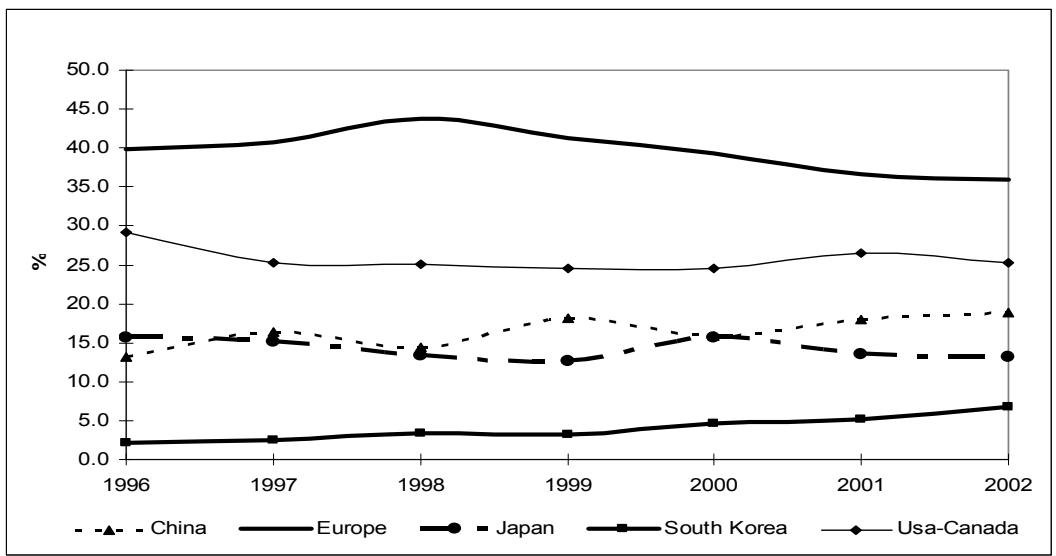

Fig. 11. Research trend per geo-economic areas measured by number of papers in nanotechnology studies classified in Material science over 1996-2002 (\% values)

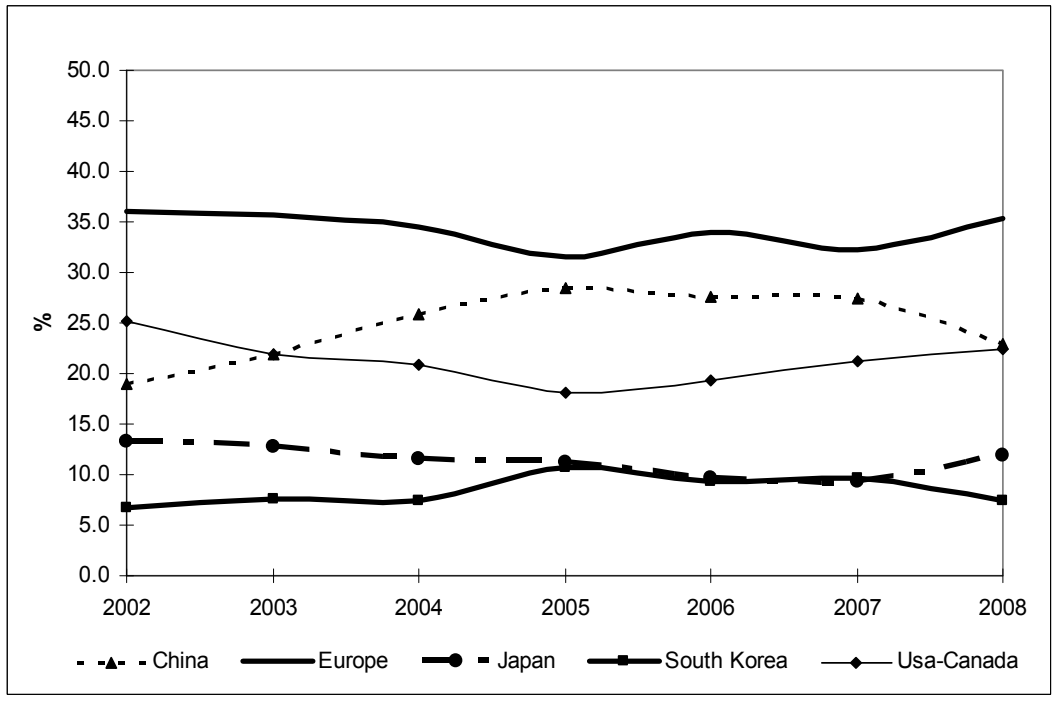

Fig. 12. Research trend per geo-economic areas measured by number of papers in nanotechnology studies classified in Material science over 2002-2008 (\% values) 


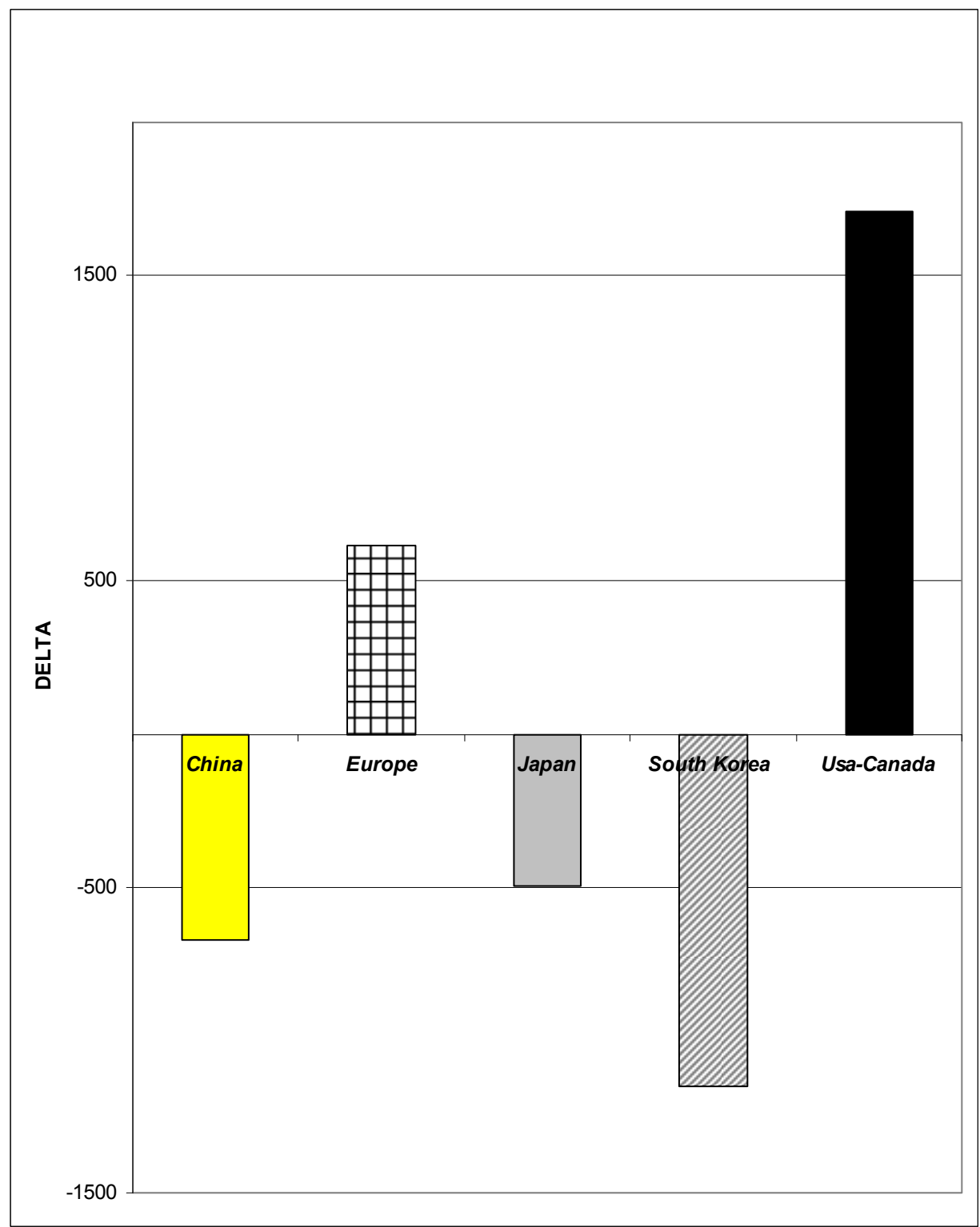

Note: DELTA is the difference between (scientific products in nanotechnology study produced in domestic research centres of the country A with foreign institutions) and (scientific products produced by other geo-economic areas in collaboration with research centres of the country A); positive delta means high attraction capacity in nanotechnology research by the specific country, vice versa negative delta means country with intensive collaborations in nanotechnology research with foreign labs.

Fig. 13. Research attraction capacity of foreign scholars in nanotechnology research per geoeconomic areas 1996-2008 period 


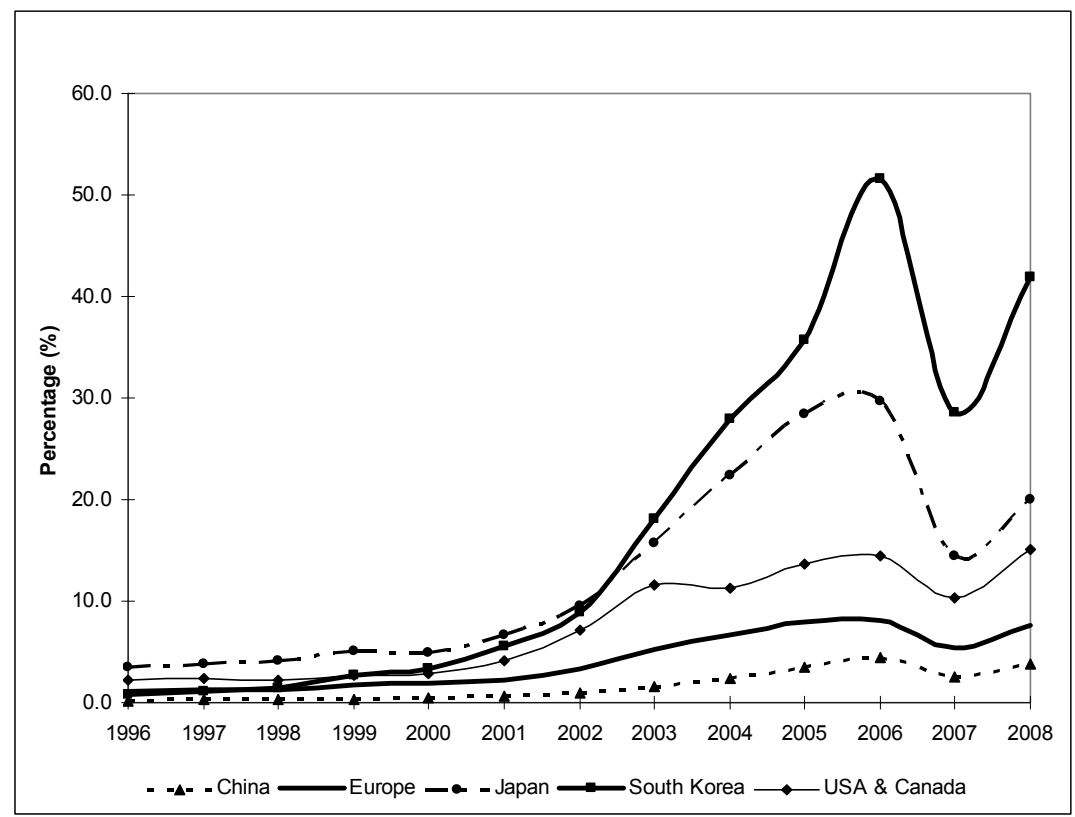

Fig. 14. Scientific products in NSTs per million people across geo-economic areas over 19962008

\section{Discussion}

The main results of this research are:

- Europe and USA-Canada have the highest number of nanotechnology research centres, although the key role of China has been increasing over time, surpassing Japan.

- Nanotechnology studies in Material Science over 1996-2008 period have a higher scientific production in comparison with other macro subject areas, however there is a relative production increase in the research fields of "Chemistry and Medicine" and a relative production decrease in "Material Sciences".

- The driving geo-economic areas of nanotechnology studies in "Chemistry and Medicine" are Europe and North America, whereas the relative highest rate of growth is in China and South Korea ${ }^{14}$.

- Main nanotechnology research fields applied in "Chemistry and Medicine" are: Chemistry $(\sim 53 \%)$, Chemical Engineering ( 23\%), Biochemistry, Genetics and Molecular Biology ( 14\%).

- Europe and North America in nanotechnology research have a high attraction capacity of scholars from other geo-economic areas, whereas the country with the highest number of collaborations in nanotechnology studies with leading countries is South Korea (over 1996-2008).

\footnotetext{
${ }^{14}$ However, these results based on a linear trends are only an approximation such that should be further examined if they have to be used for forecasting purpose.
} 
Why Europe and USA-Canada have higher production in nanotechnology studies?

The determinant can be due to the higher rate of investments in Public R\&D in NSTs, that according to Roco (2005) in 2004 were about $\$ 1,100 \mathrm{M}$ in the USA (3.7 \$/Capita) $)^{15} \sim \$ 1,050 \mathrm{M}$ in EU-25 (2.3 \$/Capita), $\sim \$ 950 \mathrm{M}$ in Japan (7.4 \$/Capita), $\$ 250 \mathrm{M}$ in China (0.2 \$/Capita) and $\sim \$ 300 \mathrm{M}$ in Korea (6.2 \$/Capita). According to Huang et al. (2004) the United States have over 60 percent of world nanotechnology patents.

Why relative NSTs research trend in "Chemistry and Medicine" has been increasing, while "Material Sciences" studies has been decreasing?

Results on the temporal relative decrease of NSTs studies in "Material science" and increase in "Chemistry and Medicine" can be due to the technology trajectory that have been passing from the invention phase of new nanomaterials to the innovation phase focused on innovative applications in biochemistry, medicine, genetics, etc. In other words, NSTs is a dynamic "new technological system" (Freeman and Soete, 1987, p. 67): some inventions might have become radical and incremental innovations applied in several fields such as chemical engineering and medicine. Islam and Miyazaki (2010) argue that: "US has gained much strength in bionanotechnology research relative to other domains, and the other regions (e.g. the EU, Japan, China, South Korea and India) have gained their research strength in nanomaterials, nanoelectronics and nanomanufacturing and tools" (p. 229). In addition, this new "technological system" has different inner nanotechnology trajectories that by cross-fertilization have been generating new "converging technologies" (Bainbridge and Roco, 2006) that are in the first phase of the S-shaped curve of growth (Roco, 2007), i.e. before the point of inflection: this phase is characterized by high level of exponential growth that will generate new radical and incremental innovations in not-too-distant future. Roco (2007) also conjectures that the dynamics of nanotechnology outcomes will pass the point of inflection after the year 2020 or thereabouts.

Figure 14 confirms that the development curve of nanotechnology production is not linear, but S-shaped over 1996-2008 period, characterized by a disequilibrium pattern of growth. In particular, figure 14 shows the relative higher number of scientific outputs per million people in South Korea and Japan. A critical point is 2002 where the increasing trend of South Korea has been prevailing on Japan and other geo-economic players. In addition, table 1 shows that R\&D investment in nanotechnology as \$/capita is 6.2 in South Korea, lower than Japan (7.4). However, NSTs outcome in South Korea is of 27.92 scientific products per million people, a higher value than Japan (22.30). This gap is higher if the scientific performances of 2008 are considered: 41.98 scientific products (in nanotechnology) per million people in South Korea vs. 19.93 in Japan. Therefore these results show that the specificity of national sub-set of nanotechnology in South Korea has more efficiency in comparison with Japan and other geo-economic areas.

\footnotetext{
15 “The 2011 Budget provides $\$ 1.8$ billion for the National Nanotechnology Initiative (NNI), reflecting steady growth in the NNI investment. The cumulative NNI investment since 2001, including the 2011 request, now totals almost $\$ 14$ billion. Cumulative investments in Environmental, Health and Safety (EHS) research since 2005 now total over $\$ 480$ million. Cumulative investments in education and in research on ethical, legal, and other societal dimensions of nanotechnology since 2005 total over \$260 million" (US National Nanotechnology Initiative: http:/ / www.nano.gov/html/ about/funding.html, accessed 8 June 2010).
} 


\begin{tabular}{lcccc}
\hline Countries & $\begin{array}{c}\text { Specific. } \\
\text { Nanotech } \\
\text { R E D 2004 } \\
(\$ / \text { Capita) }\end{array}$ & $\begin{array}{c}\text { Nanotechnology } \\
\text { scientific products } \\
\text { per million people }\end{array}$ & $\begin{array}{c}\text { Nanotechnology } \\
\text { scientific products } \\
\text { per million people }\end{array}$ & 2004 \\
\hline USA & 3.7 & 11.28 & 15.07 & 33.60 \\
Europe & 2.3 & 6.62 & 7.65 & 15.56 \\
Japan & 7.4 & 22.30 & 19.93 & -10.63 \\
China & 0.2 & 2.40 & 3.80 & 58.33 \\
South-Korea & 6.2 & 27.92 & 41.98 & 50.36 \\
\hline
\end{tabular}

* Source: Roco (2007), pp. 3.1-3.26

Table 1. Research Investments and scientific performance in nanotechnology studies across countries

This research shows main worldwide research trends of NSTs studies, though the results could have some limits. The main one is that Scopus retrieves the first 160 results for each item (Source, Affiliation, Keyword, etc.); in addition, Scopus is a relatively new instrument for scientific literature classification and not all nanotechnology research might be included (though this limit is common with other web-based datasets).

Although "nanotechnology is still in an early phase of development" (Renn and Roco, 2006, p. 153), these results show the current growing applications of nanotechnology in some key scientific sectors, such as Chemistry and Medicine ${ }^{16}$, which may imply some ethical and social issues that Governments might need to face in the next future in order to support a sustainable development of pattern of technological innovation and economic growth as well.

Renn and Roco (2006, p. 154) argue:

As with other new technology, nanotechnology evokes enthusiasm and high expectations: for new progress in science and technology, new productive applications and economic potential on one hand; and for concerns about risks and unforeseen side effects on the other.

Renn and Roco (2006) also claim the general risks associated with nanotechnology applications, showing that the nanotechnology innovation proceeds ahead of the policy and regulatory contexts: "Governance gap is [...] especially significant for the several 'active' nanoscale structures and nanosystems that [...] have the potential to affect not only the human health and the environment but also aspects of social lifestyle human identity and cultural values" (p. 153, original emphasis). Robinson (2009) describes the notion of "Responsible Research and Innovation of nanotechnology as an opportunity to develop support tools for exploring potential co-evolutions of nanotechnology and governance arrangements. This involved the inclusion of pre-engagement analysis of potential coevolutions in the form of scenarios into interactive workshop activities with the aim of enabling multi-stakeholder anticipation of the complexities of co-evolution" (p. 1222, original emphasis).

\footnotetext{
${ }^{16}$ According to de Miranda Santo et al. (2006) "many areas will suffer impacts caused by Nanoscience and Nanotechnology [...] as health, chemistry and petrochemicals, computing, Energy, agribusiness, metallurgy, textiles, environmental protection, among other" (p. 1020).
} 
No doubt that information analysis and foresight studies for research trends and scientific collaboration in NSTs are a hard work since this technological system is characterized by "interdisciplinarity" and "pervasiveness" (Salerno et al., 2008, p. 1206, 1208, and 1220, passim) in the current disequilibrium phase of growth. In presence of these scientific and analytical issues, further research about these research trends is needed to strengthen this important topic in economics of innovation in order to design provident innovation policy and governance practices supporting these "new converging innovations" (cf. Bainbridge and Roco, 2006), within the technological system of nanotechnology, aimed at driving sustainable paths of growth for modern economies.

\section{Acknowledgements}

The authors thank Prof. S. Coluccia and Dott. L. Bertinetti (University of Torino, Italy) for helpful comments and suggestions as well as Prof. S. Rolfo of CERIS-CNR for supporting this research field. Ugo Finardi acknowledges the continuous support of Prof. Salvatore Coluccia and the present support of Prof. Livio Battezzati (both from University of Torino, Italy). Mario Coccia thanks the Ceris-CNR staff. The present work is the extension and reelaboration of our paper "Current trends in nanotechnology research across worldwide geoeconomic players" published on "The Journal of Technology Transfer" (doi: 10.1007/s10961011-9219-6); the Editor-in-chief of The Journal of Technology Transfer, Prof. Al Link, is acknowledged. The authors in parentheses (MC: Mario Coccia, UF: Ugo Finardi and DM: Diego Margon) have made substantial contributions to the following tasks of research: Conception (MC); Design (MC and UF); theoretical framework (UF); acquisition of data (UF and $\mathrm{DM}$ ); modeling and analysis of data (MC); elaboration data and graphs (DM), interpretation of data (MC and UF); drafting of the manuscript (MC and UF); critical revision of the manuscript for important intellectual content (MC); statistical analysis (MC), supervision (MC). Usual disclaimer applies.

Mario Coccia is an economist at the National Research Council of Italy (Ceris-CNR), Georgia Institute of Technology (Atlanta, USA), and visiting professor of industrial organization at the University of Piemonte Orientale (Italy). He has been research fellow at the Max Planck Institute of Economics (Germany), visiting professor at the Polytechnics of Torino (Italy) and University of Piemonte Orientale "A. Avogadro", visiting researcher at the University of Maryland (College Park, USA), Institute for Science and Technology Studies at the University of Bielefeld (Germany) and University of Yale. He has written extensively on Economics of Innovation and Science, Technometrics, Technological and Economic Forecasting; his research publications include more than one hundred and fifty papers in seven disciplines.

Ugo Finardi holds a MSc in Industrial Chemistry and a Ph.D. in Materials Sciences and Technology. He is at present Research Assistant at the Department of Inorganic, Phisical and Materials Chemistry at the University of Torino and Fellow of Ceris-CNR. He performs research in the fields of Innovation Studies and Management of Research, with a particular focus on research and industrialization of new materials, technology transfer and regional systems of innovation.

Diego Margon is a technician at the National Research Council of Italy (Ceris-CNR). He is specialized in data collection and data analysis applying statistical software packages, and has published several technical reports about technological topics. 


\section{Appendix A}

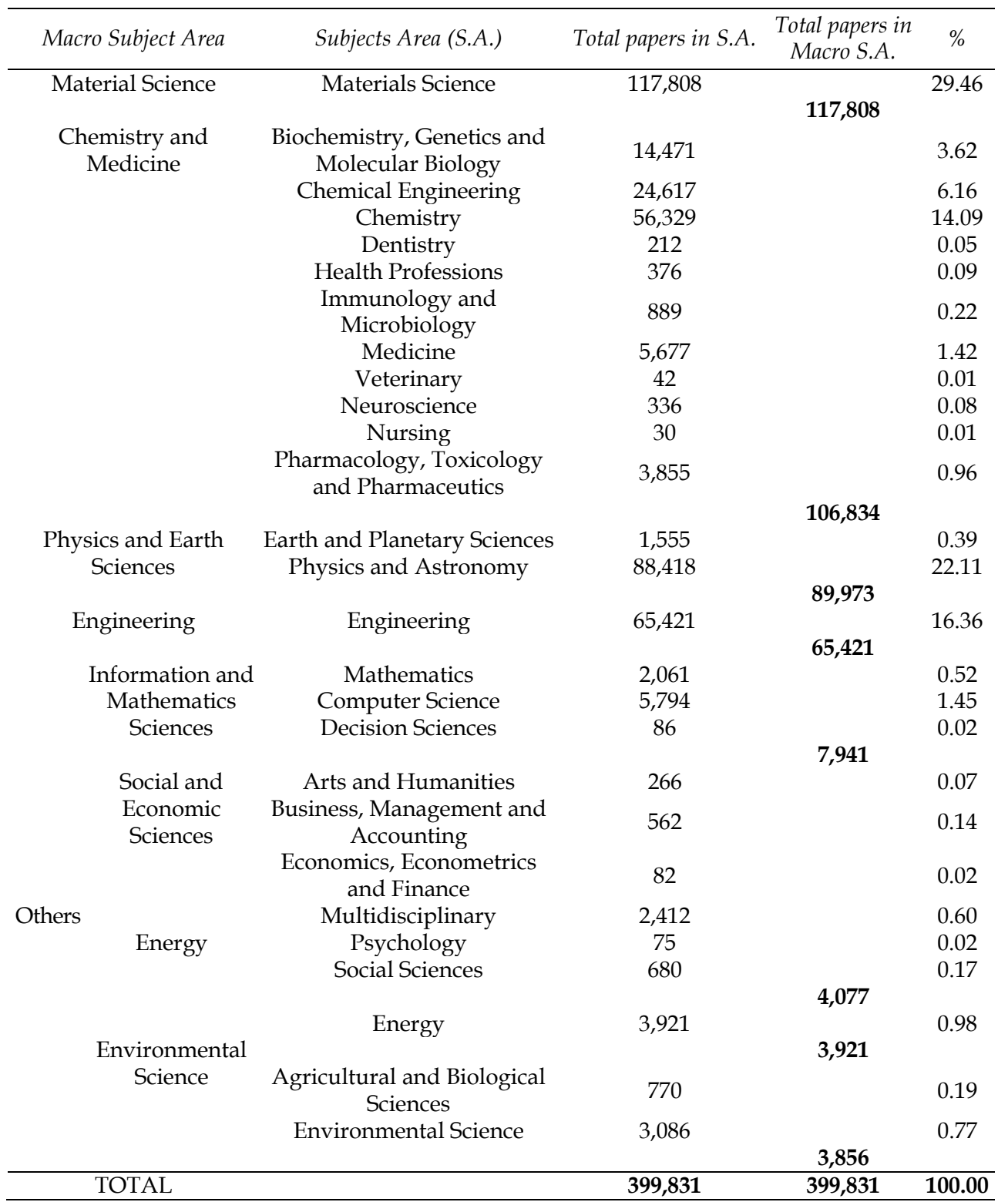

Note: Scopus classifies journals in major subject areas, e.g. "Energy". Journals can be allocated to multiple subject areas as appropriate to their scope. The subject areas contain scientific products concerning nanotechnology studies.

Table 1A. Scientific output in NSTs studies over 1996-2008 per subject areas and macro subject areas 
Nano Research Trends of Critical Scientific Fields Across

\begin{tabular}{|c|c|c|c|c|c|c|c|c|c|c|}
\hline \multirow[b]{2}{*}{ Year } & \multicolumn{2}{|l|}{ China } & \multicolumn{2}{|l|}{ Europe } & \multicolumn{2}{|l|}{ Japan } & \multicolumn{2}{|c|}{ South Korea } & \multicolumn{2}{|c|}{ USA-Canada } \\
\hline & Labs & $\begin{array}{l}\text { Scientific } \\
\text { products }\end{array}$ & Labs & $\begin{array}{l}\text { Scientific } \\
\text { products* }\end{array}$ & Labs & $\begin{array}{l}\text { Scientific } \\
\text { products }^{*}\end{array}$ & Labs & $\begin{array}{l}\text { Scientific } \\
\text { products }^{*}\end{array}$ & Labs & $\begin{array}{l}\text { Scientific } \\
\text { products }\end{array}$ \\
\hline 1996 & 59 & 210 & 128 & 675 & 117 & 430 & 20 & 37 & 128 & 673 \\
\hline 1997 & 91 & 312 & 134 & 856 & 122 & 483 & 28 & 51 & 132 & 700 \\
\hline 1998 & 97 & 414 & 139 & 874 & 125 & 519 & 33 & 68 & 133 & 670 \\
\hline 1999 & 105 & 467 & 137 & 1135 & 118 & 645 & 48 & 124 & 133 & 841 \\
\hline 2000 & 113 & 612 & 142 & 1234 & 109 & 621 & 55 & 159 & 130 & 878 \\
\hline 2001 & 115 & 780 & 144 & 1414 & 116 & 848 & 73 & 260 & 142 & 1294 \\
\hline 2002 & 114 & 1185 & 140 & 2122 & 109 & 1214 & 82 & 425 & 149 & 2264 \\
\hline 2003 & 112 & 2001 & 144 & 3404 & 107 & 1993 & 80 & 864 & 137 & 3696 \\
\hline 2004 & 123 & 3070 & 148 & 4313 & 112 & 2836 & 86 & 1330 & 142 & 3607 \\
\hline 2005 & 132 & 4476 & 143 & 5167 & 113 & 3607 & 84 & 1705 & 141 & 4375 \\
\hline 2006 & 132 & 5760 & 147 & 5280 & 118 & 3780 & 90 & 2460 & 143 & 4601 \\
\hline 2007 & 135 & 3324 & 147 & 3556 & 112 & 1834 & 89 & 1363 & 140 & 3301 \\
\hline 2008 & 133 & 4864 & 151 & 4980 & 115 & 2534 & 89 & 2000 & 149 & 4819 \\
\hline Total & & & & & & & & & & \\
\hline $\begin{array}{l}1996- \\
2008\end{array}$ & 1,461 & 27,475 & 1,844 & 35,010 & 1,493 & 21,344 & 857 & 10,846 & 1,799 & 31,719 \\
\hline
\end{tabular}

* Scientific products are papers, proceedings, etc.

Table 2A. Cumulative NSTs research labs and their scientific products in nanotechnology studies over 1996-2008 across geo-economic areas

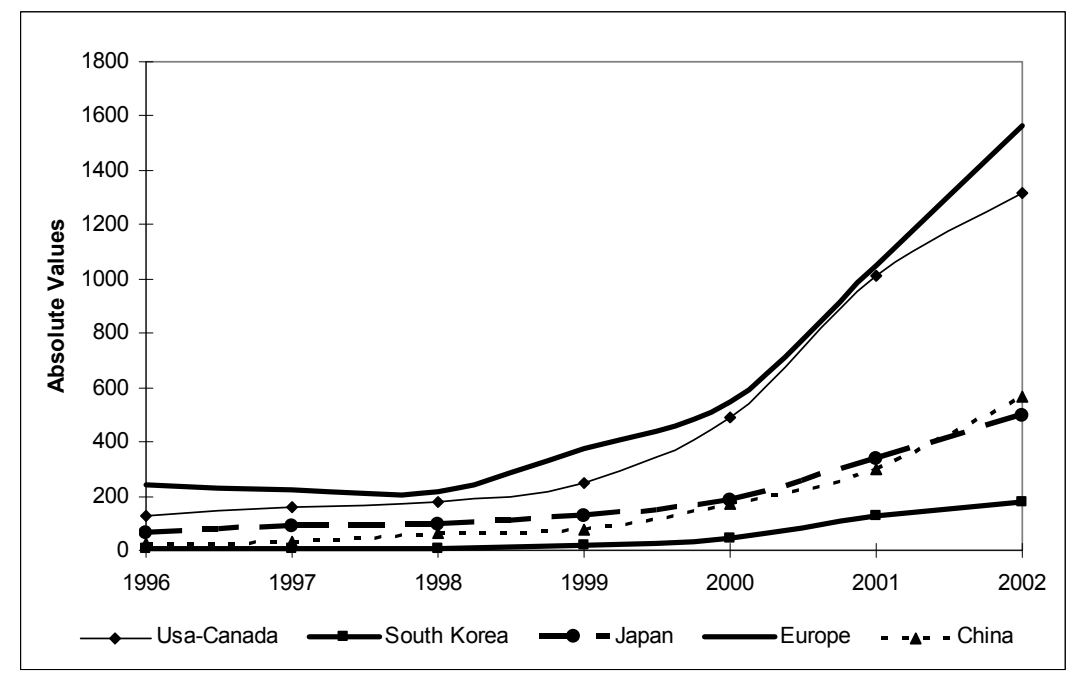

Fig. 1A. Research trend per geo-economic areas measured by number of scientific products concerning NSTs studies classified in Chemistry and Medicine over 1996-2002 (absolute values) 


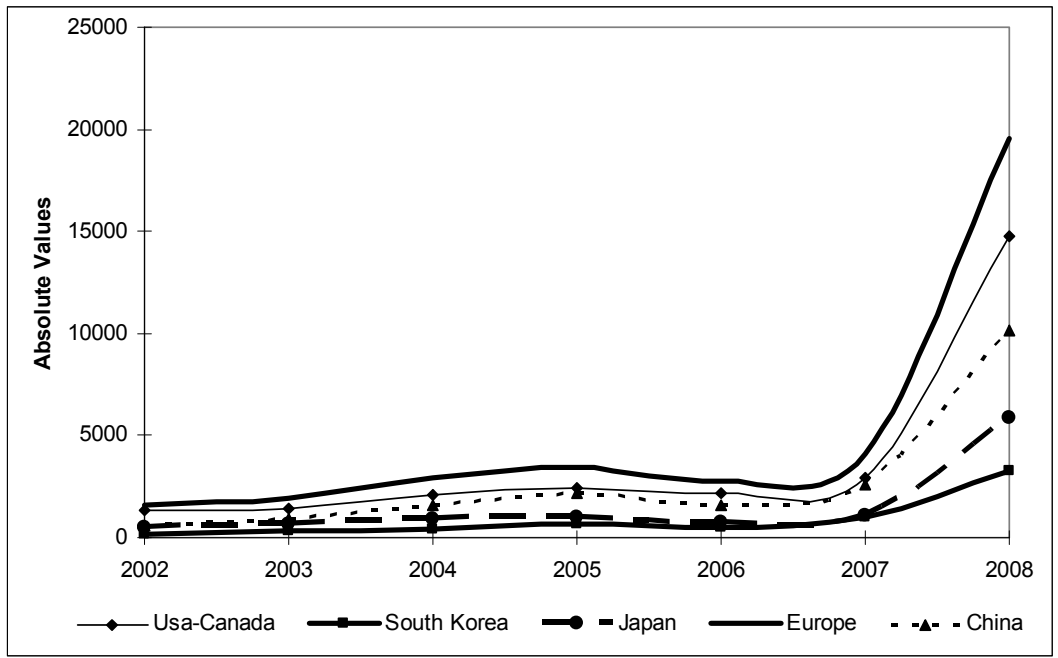

Fig. 2A. Research trend per geo-economic areas measured by number of scientific products concerning NSTs studies classified in Chemistry and Medicine over 2002-2008 (absolute values)

\section{References}

Avenel E., Favier A.V., Ma S., Mangematin V., Rieu C., "Diversification and hybridization in firm knowledge bases in nanotechnologies", Research Policy, vol. 36, n. 6, pp. 864-870

Bainbridge W.S., Roco M.C. (Eds.) (2006), Managing nano-bio-info-cogno innovations, converging technologies in society, Springer, Berlin.

Balzani V. (2005), "Nanoscience and Nanotechnology: A personal View of a Chemist”, Small, vol. 1, n. 3, pp. 278-283.

Bertinetti L., Tampieri A., Landi E., Ducati C., Midgley P.A., Coluccia S., Martra G. (2006), "Surface structure, hydration, and cationic sites of nanohydroxyapatite: UHR-TEM, IR, and microgravimetric studies", Journal of Physical Chemistry C, vol. 111, n. 10, pp. 4027-4035.

Bozeman B., Laredo P., Mangematin V. (2007), "Understanding the emergence and deployment of "nano" S\&T", Research Policy, vol. 36, n. 6, pp. 807-812.

Braun T., Schubert A., Zsindely, s. (1997), "Nanoscience and nanotechnology on balance", Scientometrics, vol. 38, n. 2, pp 321-325.

Celotti G., Tampieri A., Sprio S., Landi E., Bertinetti L., Martra G., Ducati C. (2006), "Crystallinity in apatites: how can a truly disordered fraction be distinguished from nanosize crystalline domains?", Journal of Materials Science-Materials in Medicine, vol. 17, n. 11, pp. 1079-1087.

Coccia M. (2012) "Evolutionary dynamics of the production of nanotechnology research across worldwide economic players" Technological Analysis and Strategic Management, Forthcoming

Coccia M. (2011) "Driving scientific forces for current and future micro-technological revolutions and social transformations" Mimeo at Georgia Institute of Technology (Atlanta, USA). 
Coccia M., Finardi U., Margon D. (2011), “Current trends in nanotechnology research across worldwide geo-economic players", Journal of Technology Transfer, DOI 10.1007/s10961-011-9219-6

de Miranda Santo M., Massari Coelho G., Maria dos Santos D., Fellows Filho L. (2006), “Text mining as a valuable tool in foresight exercises: A study on nanotechnology", Technological Forecasting and Social Change, vol. 73, n. 8, October, pp. 1013-1027.

Eigler D.M., Schweizer E.K. (1990), "Positioning single atoms with a scanning tunnelling microscope", Nature, n. 344, pp. 524-526.

Evangelisti C., Vitulli G., Schiavi S., Vitulli M., Bertozzi S., Salvadori P., Bertinetti L., Martra G. (2007), "Nanoscale $\mathrm{Cu}$ supported catalysts in the partial oxidation of cyclohexane with molecular oxygen", Catalysis Letters, vol. 116, n. 1-2, pp. 57-62.

Feynman R.P. (1960), "There's plenty of room at the bottom", Engineering and Science vol. 23, Feb., pp. 22-36.

Finardi U. (2011), "Time relations between scientific production and patenting of knowledge. The case of nanotechnologies", Scientometrics, vol. 89, n. 1, pp. 37-50

Freeman C., Soete L. (1987), Technical Change and Full Employment, Basil Blackwell, Oxford (UK).

Glenn J.C. (2006), "Nanotechnology: Future military environmental health considerations", Technological Forecasting and Social Change, vol. 73, n. 2, February, pp. 128-137.

Goddard III W., Brenner D., Lyshevski S., Iafrate G. (Eds.) (2007), Handbook of Nanoscience, Engineering and Technology, Second Edition, Taylor and Francis Group.

Huang Z., H. Chen, Roco M. C., 2004, “Longitudinal patent analysis for nanoscale science and engineering in 2003: country, institution and technology field analysis based on USPTO patent database" Journal of nanoparticle research, vol. 6, n. 4, pp. 325-354.

Iijima S. (1991), “Helical microtubules of graphitic carbon”, Nature, n. 354, pp. 56-58.

Islam N. and Miyazaki K. (2009), Nanotechnology innovation system: Understanding hidden dynamics of nanoscience fusion trajectories, Technological Forecasting \& Social Change, vol. 76, n. 1, pp. 128 - 140

Islam N., Miyazaki K. (2010), "An empirical analysis of nanotechnology research domains”, Technovation, vol. 30, n. 4, pp. 229-237.

Kostoff R N., Stump J.A., Johnson D., Murday J.S., Lau C.G.Y., Tolles W.M. (2006), “The structure and infrastructure of the global nanotechnology literature", Journal of Nanoparticle Research, vol. 8, n. 3-4, pp. 301-321.

Kostoff R.N., Koytcheff R.G., Lau C.G.Y. (2007), "Global nanotechnology research metrics”, Scientometrics, vol. 70, n. 3, pp. 565-601.

Kostoff R.N., Koytcheff R.G., Lau C.G.Y. (2007a), “Global nanotechnology research literature overview", Technological Forecasting \& Social Change, vol. 74, n. 9, pp. 1733-1747.

Kroto H.W., Heath J.R., O'Brien S.C., Curl R.F., Smalley R.E. (1985), “C60: Buckminsterfullerene", Nature, n. 318, pp. 162-163.

Leydesdorff L. (2008), "The delineation of nanoscience and nanotechnology in terms of journals and patents: A most recent update", Scientometrics, vol. 76, n. 1, pp. 159-167.

Leydesdorff L., Zhou P. (2007), "Nanotechnology as a field of science: its delineation in terms of journals and patents", Scientometrics, vol. 70, n. 3, pp. 693-713.

Libaers D., Meyer M., Geuna A. (2006), "The Role of University Spinout Companies in an Emerging Technology: The Case of Nanotechnology", The Journal of Technology Transfer, vol. 31, n. 4, pp. 443-450.

Linstone H.A. (2011), “Three eras of technology foresight”, Technovation vol. 31, n. 2-3, pp. 69 - 76 
Pilkington A., Lee L.L., Chan C.K., Ramakrishna S. (2009), “Defining key inventors: A comparison of fuel cell and nanotechnology industries", Technological Forecasting and Social Change, vol. 76, n. 1, January, pp. 118-127.

Renn O., Roco M.C. (2006), "Nanotechnology and the need for risk governance", Journal of Nanoparticle Research, vol. 8, n. 2, pp. 153-191.

Rickerby D.G., Morrison M. (2007), "Nanotechnology and the environment: A European perspective", Science and Technology of Advanced Materials, vol. 8, n. 1-2, pp. 19-24.

Robinson D.K.R. (2009), “Co-evolutionary scenarios: An application to prospecting futures of the responsible development of nanotechnology" Technological Forecasting and Social Change, vol. 76, n. 9, pp. 1222-1239.

Roco M.C. (2005), "International perspective on government nanotechology funding in 2005", Journal of Nanoparticle Research, vol. 7, n. 6, pp. 707-712.

Roco M.C. (2007), "National Nanotechnology Initiative. Past, Present, Future”, in W. Goddard III, D. Brenner, S. Lyshevski \& G. Iafrate (Eds), Handbook of Nanoscience, Engineering and Technology, Second Edition, Taylor and Francis Group, Chp. 3, pp. 1-26.

Roco M.C. (2008), "Possibilities for global governance of converging technologies", Journal of Nanoparticle Research, vol. 10, n. 1, pp. 11 - 29

Rogers, J.D. (2010) "Citation analysis of nanotechnology at the field level: implications of R\&D evaluation" Research evaluation, vol. 19, n.4, pp. 281-290.

Salerno M., Landoni P., Verganti R. (2008), “Designing foresight studies for Nanoscience and Nanotechnology (NST) future developments", Technological Forecasting and Social Change, vol. 75, n. 8, October, pp. 1202-1223.

Schultz L.I. and Joutz F.L. (2010), "Methods for identifying emerging General Purpose Technologies: a case study of nanotechnologies", Scientometrics vol. 85, n. 1, pp. 155 - 170

Scopus (2010), http:/ / www.scopus.com, accessed April 2010.

Shea C.M., Grindle G. and Elmslie B. (2011), "Nanotechnology as a general-purpose technology: empirical evidence and implications", Technology Analysis E Strategic Management, vol. 23, n. 2, pp. 175 - 192

Siegel R.W., Hu E., Roco M.C. (1999), Nanostructure Science and Technology, Springer, Dordrecht, The Netherland.

Taniguchi N. (1974), "On the Basic Concept of Nano-Technology", Proceedings International Conference Production Engineering, Part II, Japan Society of Precision Engineering, Tokyo.

Tegart G. (2009), "Energy and nanotechnologies: Priority areas for Australia's future", Technological Forecasting and Social Change, vol. 76, n. 9, November, pp. 1240-1246.

US National Nanotechnology Initiative (2010), http:/ / www.nano.gov/, accessed June 2010.

van Merkerk R.O., van Lente H. (2005), “Tracing emerging irreversibilities in emerging technologies: The case of nanotubes", Technological Forecasting and Social Change, vol. 72, n. 9, November, pp. 1094-1111.

Yanagisawa T., Shimizu T., Kuroda K., Kato C. (1990), "The preparation of Alkyltrimethylammonium-Kanemite Complexes and Their Conversion to Microporous Materials", Bulletin of the Chemical Society of Japan, vol. 63, n. 4, pp. 988-992.

Zecchina A., Groppo E., Bordiga S. (2007), "Selective Catalysis and Nanoscience: An Inseparable Pair", Chemistry- A European Journal, vol. 13, n. 9, pp. 2440-2460. 


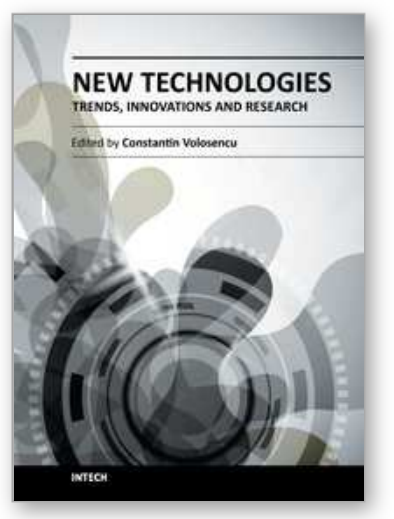

\author{
New Technologies - Trends, Innovations and Research \\ Edited by Prof. Constantin Volosencu
}

ISBN 978-953-51-0480-3

Hard cover, 396 pages

Publisher InTech

Published online 30, March, 2012

Published in print edition March, 2012

The book "New Technologies - Trends, Innovations and Research" presents contributions made by researchers from the entire world and from some modern fields of technology, serving as a valuable tool for scientists, researchers, graduate students and professionals. Some practical applications in particular areas are presented, offering the capability to solve problems resulted from economic needs and to perform specific functions. The book will make possible for scientists and engineers to get familiar with the ideas from researchers from some modern fields of activity. It will provide interesting examples of practical applications of knowledge, assist in the designing process, as well as bring changes to their research areas. A collection of techniques, that combine scientific resources, is provided to make necessary products with the desired quality criteria. Strong mathematical and scientific concepts were used in the applications. They meet the requirements of utility, usability and safety. Technological applications presented in the book have appropriate functions and they may be exploited with competitive advantages. The book has 17 chapters, covering the following subjects: manufacturing technologies, nanotechnologies, robotics, telecommunications, physics, dental medical technologies, smart homes, speech technologies, agriculture technologies and management.

\title{
How to reference
}

In order to correctly reference this scholarly work, feel free to copy and paste the following:

Mario Coccia, Ugo Finardi and Diego Margon (2012). Nano Research Trends of Critical Scientific Fields Across Leading Worldwide Geo-Economic Players and Their Spatial Interactions, New Technologies - Trends, Innovations and Research, Prof. Constantin Volosencu (Ed.), ISBN: 978-953-51-0480-3, InTech, Available from: http://www.intechopen.com/books/new-technologies-trends-innovations-and-research/current-scientifictrajectories-and-interactions-between-main-world-geo-economic-players-in-nanotech

\section{INTECH}

open science | open minds

\author{
InTech Europe \\ University Campus STeP Ri \\ Slavka Krautzeka 83/A \\ 51000 Rijeka, Croatia \\ Phone: +385 (51) 770447 \\ Fax: +385 (51) 686166 \\ www.intechopen.com
}

\author{
InTech China \\ Unit 405, Office Block, Hotel Equatorial Shanghai \\ No.65, Yan An Road (West), Shanghai, 200040, China \\ 中国上海市延安西路65号上海国际贵都大饭店办公楼 405 单元 \\ Phone: +86-21-62489820 \\ Fax: +86-21-62489821
}


(C) 2012 The Author(s). Licensee IntechOpen. This is an open access article distributed under the terms of the Creative Commons Attribution 3.0 License, which permits unrestricted use, distribution, and reproduction in any medium, provided the original work is properly cited. 